\title{
DYNAMIC CONTROL OF DISCHARGE ENERGY DURING WEDM FOR THE PURPOSE OF ELIMINATING VIBRATIONS OF THE WIRE TOOL ELECTRODE
}

\author{
L'uboslav STRAKA, Patrik KUCHTA \\ Technical University of Kosice
}

\begin{abstract}
:
Production in all industry fields is currently affected by new scientific and technical knowledge and the requirements for its rapid deployment. In many cases, the most modern and highly sophisticated technical systems are applied. Simultaneously, fully automated production systems are rather successfully used and progressive production technologies are implemented. In most cases, there is an integral part of a management system that operates the challenging technological processes. These processes would not be executable without the system's precise control, which provides a suitable precondition for ensuring the high quality of manufactured products. However, the customer's demanding requirements are not always met. These involve increased requests for the quality of the final product due to the reduction of the tolerance band and application of high-strength materials. This paper aims to describe one of the solutions by which it is possible to achieve a higher quality of the machined surface after wire electrical discharge machining (WEDM). The solution proposes that through dynamic management, the WEDM process eliminates the vibrations of the wire tool electrode and thereby achieves a substantial increase in the quality of the eroded area in terms of its geometric accuracy. With the support of an extensive database of information with precise exchange of information, the proposed system will allow to control the electro discharge process with regard to the optimal way of operation of the electro discharge machine on the basis of individually selected conditions.
\end{abstract}

Key words: acoustic emission, dynamic control, Main Technological Parameters (MTP), Wire Electrical Discharge Machining (WEDM), Wire Tool Electrode (WTE)

\section{INTRODUCTION}

Modern engineering production, which uses special methods and technical equipment for machining highstrength materials, is characterized by high-quality products. The attention is focused on such machining processes, in which the mechanical properties of a commodity and a tool have no limits [2]. This mainly concerns the machining manners where the material's degree of machinability is determined solely by its physical properties, such as thermal and electrical conductivity, melting point [22], atomic valence, etc. Despite the use of these highly sophisticated technologies, the customer's requirements for quality are not always met in terms of dimensional and geometric accuracy [3]. These shortcomings are due to the unsatisfactory design accuracy of the machine tool, an inadequate setting of the main and the managing technological parameters, or the poor software control of the cutting process [4]. Electrical discharge machining devices are especially prone to these types of faults. Since WEDM is characterized by a high quality of the machined surface, even the smallest deviation from the required dimension or shape has a significant impact on the final quality of the finished product $[5,23]$. One of the causes of this poor quality is the vibration of the wire tool electrode. Although many experimental studies have been carried out in this particular field, the most satisfying results have not been delivered yet. The experiments showed that the wire tool electrode (WTE) vibrations vastly affect the geometrical deviation of the eroded area $[9,11]$. Numerous experiments also demonstrated that one of the main reasons for the WTE vibrations is the application of an improper WTE tensioning force. Furthermore, they found out that the magnitude of the WTE tensioning force should be close to the critical values. This leads to a substantial reduction in the oscillation amplitude of the wire tool electrode during WEDM, resulting in a serious improvement of the quality of the eroded surface in terms of geometric accuracy. In this regard, it is important to 
state that the WTE tensioning force can only be increased up to a certain point. If the strength of the wire material is exceeded, it will rupture [17]. That could, in turn, lead to an extension of the total machining time and thus to an unpleasant effect on the overall WEDM productivity. Multiple input factors influence the geometrical accuracy of the eroded area $[6,10]$. In many cases, we cannot exactly identify the principal originators of these geometrical errors. Mostly there are only conjectures and speculations. However, one thing is known for certain. All of these input factors have a mutual denominator, and that is the precision of the WTE management, which is mainly affected by hardware accuracy and software precision of wire movement control [18-20]. No less important is the setting of the main technological parameters (MTP), which are both primarily and secondarily involved in WTE vibrations, which subsequently causes geometric inaccuracy of the eroded surface. Therefore, the experimental research aimed to identify the principal cause of these WTE vibrations in order to design a fitting solution for their elimination.

\section{LITERATURE REVIEW}

It is essential to focus on the originator of WTE vibrations if we want to find proper solutions to eliminate them. Based on a literary resources analysis, discharge energy was considered to be the primary causer. The energy is produced by an electric impulse generator. Nowadays, electro-erosive machining uses various types of these electric impulse generators. Most of them control the performance parameters to maximize cutting power. This new type of electric impulse generator that is applicable in the conditions of the electro-erosive process is described by the authors Qudeiri, J.E.A. et al. [15]. However, the main deficiency of this electric impulse generator is the absence of an algorithm that would take into account the minimization of WTE vibrations. A different point of view on this issue was presented by researchers Yan, M.T. et al. [27]. Their research concentrated on the development of a new type of impulse generator. This impulse generator differs from the standard types mainly in its control algorithm, which not only maximizes EDM power but also includes an algorithm that minimizes the roughness of the eroded surface. A similar type of electric impulse generator is also described by the authors Świercz, D.O. et al. [24]. Nevertheless, in both cases, there is no criterion in the control algorithm of the impulse generator for minimizing errors in the geometric accuracy of the eroded surface by eliminating WTE vibrations. A special type of generator was also in a developing process carried out by Barik, S.K. et al. [1]. Their electric impulse generator allows a power adjustment according to special quality requirements of the eroded area, but again lacks the possibility of eliminating WTE vibrations. Another significant disadvantage of this generator is that it allows its application only in laboratory conditions. Based on the conducted analysis in the field of development of electric impulse generators, we concluded that in the control algorithms of the ordinarily used systems for the generation of electrical impulses in electro-erosive processes, the criterion for the minimization of WTE vibrations is absent. Therefore, our research aimed to design an algorithm for the control of dynamic discharge energy during WEDM that would minimize WTE vibrations. In terms of geometric accuracy, this should significantly contribute to increasing the final quality of the products, which are manufactured using progressive WEDM technology.

\section{MATERIAL AND WORKING METHODS}

Selection of a suitable measurement method for WTE vibrations identification during WEDM

The inaccuracy of the WTE wiring due to its deflection from the straight position is caused by forces that arise as a result of the cyclic action of electric discharges during the electro-erosive discharge process. In general, it can be assumed that the greater the thickness of the machined material, the greater the deflection of the WTE. During the electro-erosive process, the thin WTE standardly oscillates in the direction of the $X$ and $Y$ axes. The magnitude of its vibrations is directly dependent on the intensity of generated electrical pulses. Fig. 1 shows the oscillation direction of WTE during the electro-erosive process.
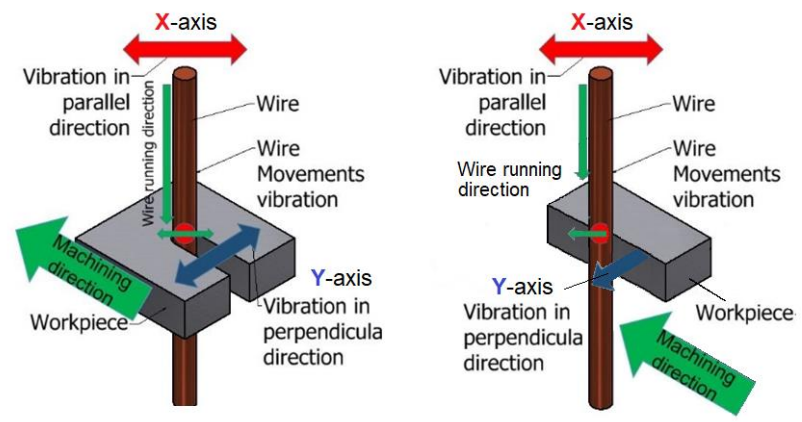

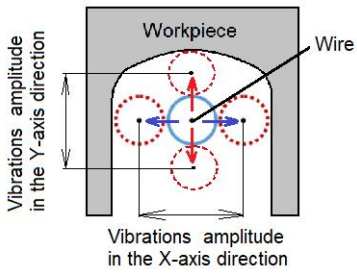

a) roughing (fullcut)

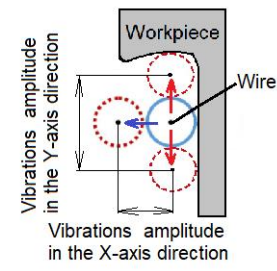

b) finishing (overcut)
Fig. 1 The direction of oscillation of the wire tool electrode during WEDM

Source: [21].

The oscillation character of the WTE differs depending on whether a full cut or an offset cut is performed. If a roughing operation is performed by a full cut, the WTE oscillation will be executed as is shown in Fig. 1a. Fig. $1 \mathrm{~b}$ shows the oscillation during the finishing process, when the WTE performs an overcut. Partial compensation for these adverse effects can be achieved by applying special measures. This is, in particular, a measure that includes the counter-force in combination with a system that ensures optimal WTE tension. Usually, tension force Fw for the WTE with material strength up to $2000 \mathrm{~N} \cdot \mathrm{mm}^{-2}$ ranges between 5 to $25 \mathrm{~N}$. Its intensity is also primarily chosen concerning the diameter and material properties of the WTE. Further reduction of WTE vibrations in this regard 
cannot be expected since, during WEDM, this force is generally chosen in the span of its limit values. However, there is a potential for the elimination of WTE vibrations by modifying the concept of electric discharges. Nevertheless, we must emphasize that this is a significant intervention in the traditional management system of generated electrical impulses during the electro-erosive process. It is necessary to look for such ways to eliminate WTE vibrations so that they do not negatively affect the performance of the electro-erosive process. On the contrary, it would be advantageous if by shortening the total machining time it could increase the economic efficiency [14]. These goals can only be achieved with the collaboration of highly sophisticated online monitoring and dynamic control systems. Currently, the information used to control the electro-erosive process is derived from the actual value parameters of electric discharge. The magnitude of the WTE tension, discharge current I, voltage $U$, working gap, and others are monitored from these parameters [7, 25]. Yet, the current setting of the values of these parameters does not take into account all the phenomena that occur at the place of electric discharge $[13,26]$. Therefore, it is crucial to include the phenomena related to WTE vibrations in the control algorithm as well.

\section{Identification of WTE vibrations during WEDM}

There are two basic approaches to identifying vibrations in practice - direct and indirect. Although the direct measurement of the magnitude of the WTE vibrations is slightly more precise compared to the indirect one, in real-life conditions of an electro discharge machine, this method results in a large number of problems. The main issue concerns the location of sensors. The accuracy of the indirect method of measuring the magnitude of the WTE vibration is, in turn, affected by interferences, which to some extent distort the results of the measurements. When applying individual measuring methods, the right choice of the measuring technique is crucial. Consequently, for the initial identification of the WTE vibrations in the experimental research, a direct measuring method was applied using a laser measuring device PDV 100 Portable Digital Vibrometer. The course of measurement of the WTE vibration during WEDM is shown in Fig. 2.

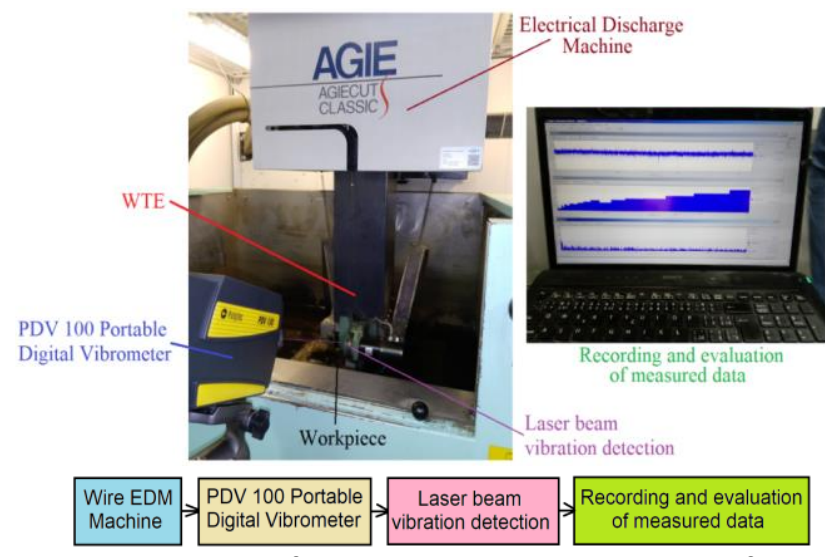

Fig. 2 Application of the direct measuring method of WTE vibrations during WEDM
A portable digital laser measuring device PDV 100 Portable Digital Vibrometer, used in the experimental measurement of WTE vibrations, can measure vibration velocities in the range from $0.5 \mathrm{~Hz}$ to $22 \mathrm{kHz}$. Thanks to its analog and digital outputs, it provides digital processing of the measured signal, which can be transferred to a PC for subsequent analysis.

\section{Analysis of recorded WTE vibration values during WEDM} Based on the results of several experimental pieces of research in the field, it has been shown that the WTE vibrations in the direction of the $X$-axis acquire slightly higher values than the vibrations in the direction of the $Y$-axis. In terms of consequences, it can be clearly stated that the WTE vibrations in the $X$-axis direction have a significantly smaller effect on the occurrence of the geometric inaccuracy of a machined surface because they are generated in its feed direction. The problem, however, is the vibrations that are generated transversely to the WTE feed direction, that is in the direction of the $Y$-axis. The magnitude of the critical oscillation frequency not only depends on the electric discharge parameters, but also on other parameters such as the thickness of the machined material, the diameter of the wire electrode, its tensile force, and many others. Therefore, this critical frequency cannot be implicitly determined. The only possibility for its identification is the application of one of the measuring methods. Fig. 3 shows the maximum WTE oscillation amplitude depending on its frequency, which occurs due to electric discharges generated during WEDM.
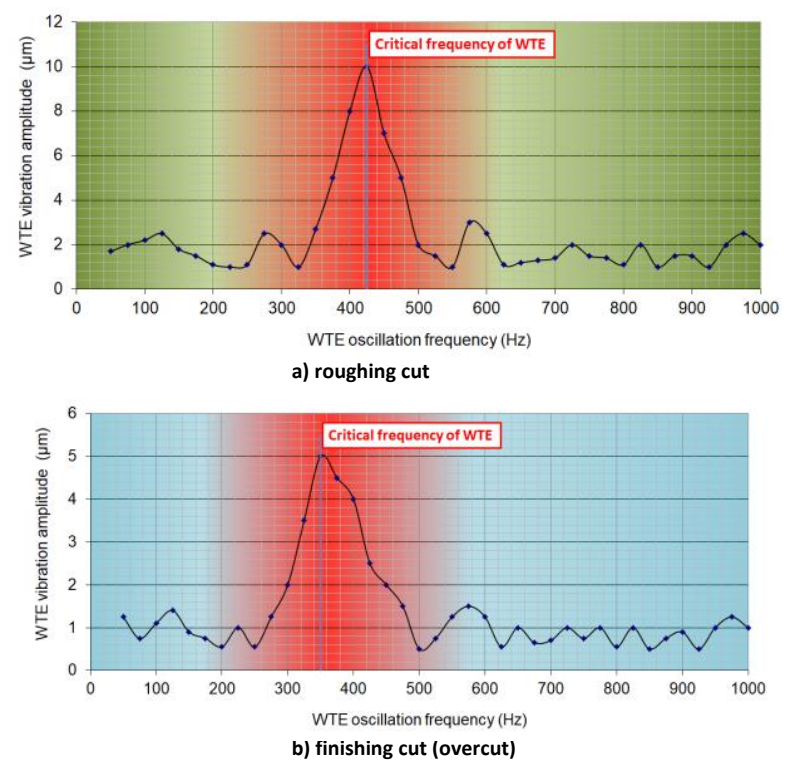

Fig. 3 Dependence of the oscillation amplitude of the wire tool electrode on the oscillation frequency of the WTE generated by the influence of electric discharges during WEDM

Based on the performed experimental measurements, it was also shown that the magnitude of the oscillation amplitude of the WTE is not directly proportional to its oscillation frequency. As can be observed from the graph in Fig. 3, its maximum value was reached by applying the critical frequency of the WTE oscillation, generated by the influence of electric discharges during WEDM. At the 
same time, its value varies not only depending on the thickness of the machined material or the properties of the WTE, but also on the machining method itself.

\section{Design of an algorithm for dynamic control of discharge energy during WEDM}

Even though there is now an increasing emphasis on the complexity of knowing the set of individual characteristics of electric discharges during WEDM, comprehensive identification of their interrelationships is still lacking. Also, there are no proposals to minimize the adverse effect of electric discharges on the quality of the machined surface after WEDM in terms of the achieved geometric accuracy. A certain solution to this problem is to design a dynamic control of the discharge energy of electrical impulses during WEDM. Its goal is to eliminate WTE vibrations, which will improve the geometric accuracy of the eroded surface. However, this requires a precise design of the control algorithm. The practical advantage of the proposed algorithm would also be to include optimization mathematical models that, based on input parameters related to material and dimensional properties of the workpiece and wire tool electrode, allow automatic adjustment of MTP for the required quality of the eroded surface in terms of its parameters of roughness.

Most importantly, a correct design of the measuring chain is necessary when designing an algorithm for dynamic control of discharge energy during WEDM in order to eliminate WTE vibrations. It is inevitable to define the sensors that will transmit the recorded signal to the control system of the electric pulse generator and the control system of the electro-erosive machine. Using the transmitted input information, they will adjust the parameters of the electric discharge so as to reduce the oscillation frequency of the WTE. The following Fig. 4 shows a design of a control algorithm for dynamic control of discharge energy during WEDM, the task of which is to minimize the vibrations of the WTE in order to achieve a higher quality of the eroded surface in terms of its geometric accuracy.

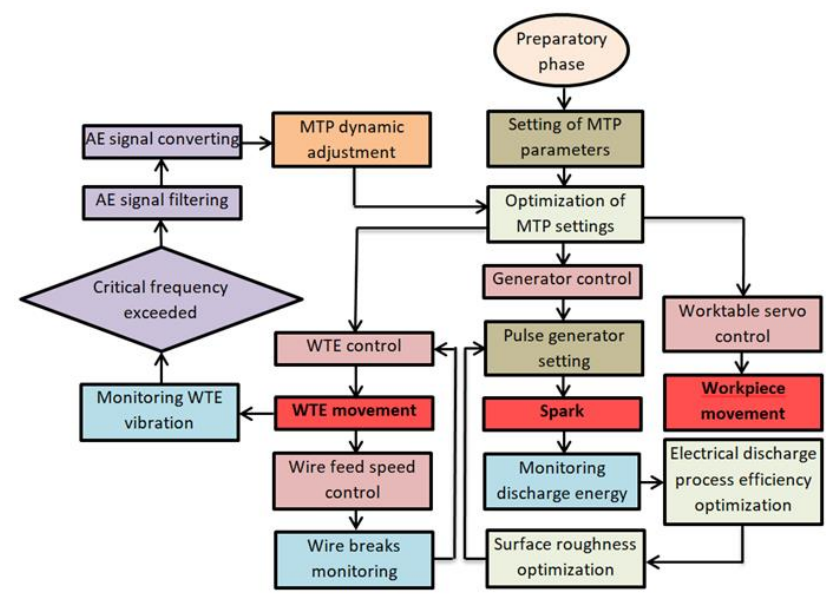

Fig. 4 Algorithm for dynamic discharge energy control during WEDM

A characteristic feature of the proposed system for dynamic control of discharge energy during WEDM is also the application of optimization techniques based on process algorithms. The use of such algorithms, which guarantee high convergence in the process of optimum identification, is particularly suitable [28]. To ensure the ideal functionality of the control system of the generated electrical pulses, a mechanism enabling the required choice of the optimization criterion must also be implemented in the system.

This means that in real action, the possibility of choosing an optimization criterion would be primarily focused on achieving high quality of the machined surface, high productivity of the electro-erosive process, high efficiency of the electro-erosive process, or a combination thereof. This requires an expert system based on an extensive information database. Its proper connection with the control system of the electro-erosive machine would thus enable efficient operation not only in serial but also in piece production.

Design of a system for dynamic control of discharge energy during WEDM in a real electro-erosive machine conditions

Regarding the use of machining processes with a non-stationary character, which also includes electro-erosive machining; highly reliable control systems are required to control the discharge energy. These systems are supposed to effectively determine the optimal parameters of the electro-erosive process with respect to the demanded quality of the machined surface. The design of such a management system should implement the principles of self-organization using advanced methods and highly sophisticated technical means. The following Fig. 5 demonstrates a schematic diagram of the connection of the $A E$ sensors with the dynamic control system of the EDM machine, which will enable the elimination of undesired WTE vibrations during WEDM.

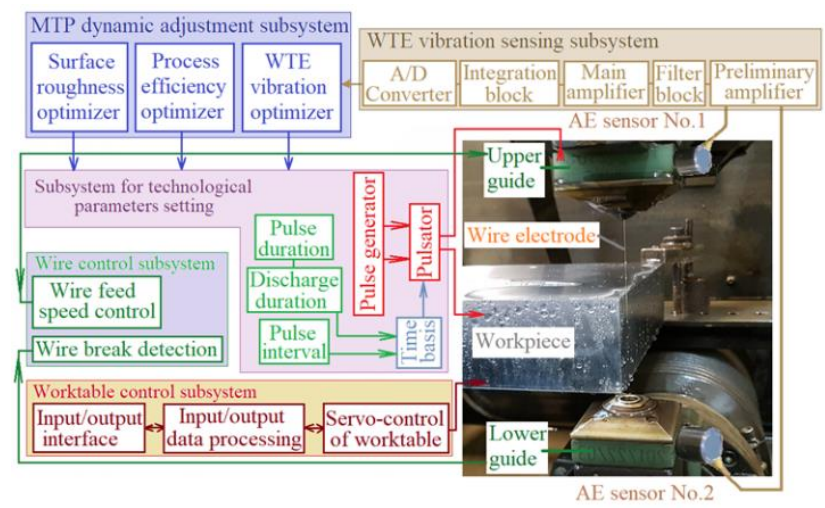

Fig. 5 Diagram of dynamic control of generated discharge energy during WEDM

A major problem with the direct method of measuring WTE vibrations during WEDM is the setting up of sensors. These would always have to be re-established for each specific condition of the machining process, which is unacceptable from a practical point of view. Therefore, despite the above-mentioned negative aspects of the indirect method of measuring WTE vibrations during the electro-erosive process, acoustic emission ( $A E$ ) sensors based on this 
method have been implemented in the proposed system. An overlap of electromagnetic interference (EMI) with the scanned $A E$ signals might be a risk in this method of indirect WTE vibration measurement. However, it is possible to filter this interfering element by a suitable intervention. Providing there is a large thickness of the machined material or some specific values of the setting of the parameters of the electric discharge, there might be a slight increase in the amplitude of the oscillation of the WTE at one of its ends. Accordingly, it seemed advantageous to place the $A E$ sensors on both the top and bottom of the WTE line. The recorded values could be distorted if the $A E$ sensor is placed on only one of the lines. The signals received from the $A E$ sensors will be transmitted to the $A / D$ converter. Subsequently, the filtered and modified information will be imported into the control system of the electro-erosive machine. Based on this input data, the machine will adjust the electric discharge parameters to increase or decrease the frequency, thereby minimizing the side effect of the maximum oscillation amplitude of the WTE.

\section{DISCUSSION}

Commonly used electro-erosive devices allow the generation of electric discharges only on the basis of current conditions in the working gap. Their control system adjusts the power characteristics of the pulse generator based on the measurement of the values of electric voltage and current in the working gap according to predetermined reference values acquired from the compiled control algorithms. However, in order to meet the demanding requirements for the quality of the machined surface in terms of its geometric accuracy, monitoring of only the mentioned parameters is insufficient [8]. Nevertheless, these demanding requirements for product quality can be met by integrating the most modern technologies for monitoring and dynamic control of the electro-erosive process $[12,16]$. This will significantly increase not only its stability and cutting performance but also the final quality of products produced by progressive WEDM technology. Concurrently, it can be stated that the application of a dynamic control system of generated electrical impulses during WEDM based on input information from the field of electric discharge is an effective means of eliminating WTE vibrations. A characteristic feature of the proposed dynamic system for controlling the generated discharge energy during WEDM is also its flexibility and openness to real-life conditions. Based on an extensive database of information, as well as the fast and accurate exchange of information with the external environment, the system will allow a controlling of the electro-erosive process with respect to the optimal way of operation of the electro-erosive machine according to the individually selected optimization criteria.

\section{CONCLUSION}

The results of several studies demonstrate that the geometric deviations of the eroded surface are mainly caused by WTE vibrations. Therefore, it was crucial to find an acceptable solution to eliminate them. Based on the outcomes of experimental research, it has been shown that a certain combination of several factors creates the maximum oscillation amplitude of WTE. Yet, this frequency is constantly changing according to special conditions. Therefore, it was necessary to focus on a solution that can dynamically respond to the change. One of the acceptable ways to identify ever-changing WTE vibrations has been the indirect method of $A E$ sensing. As the problem-solving result was considered to be the inclusion of the WTE vibrations parameter in the control algorithm as another parameter within the monitored parameters of the electro discharge process. This input parameter in the process of controlling the generated electric discharges has made it possible to acquire a new dimension in the field of increasing the final quality of products produced by progressive electro-erosive technology. Additionally, by monitoring a given process parameter, it is possible to achieve a substantial increase in the level of intelligent dynamic control of the electro-erosive process. It can also detect and subsequently, by a suitable modification of the generated electrical pulses eliminate the occurrence of undesired electrical discharges, which increase the amplitude of the oscillation of the wire electrode. This information is valuable because it allows the application of an advanced electric discharge control strategy, thus eliminating the adverse impact of improper MTP selection. Overall, the result is not only an increase in the final quality of products and ensuring the stability of the discharge process, but ultimately also an increase in the total WEDM productivity.

\section{ACKNOWLEDGMENTS}

The authors would like to thank the grant agency for supporting research work the project VEGA 1/0205/19.

\section{REFERENCES}

[1] S.K. Barik and P.S. Rao. "Design of Pulse Circuit of EDM Diesinker." International Research Journal of Engineering and Technology, vol. 3(5), pp. 2762-2765, 2016.

[2] F. Botko, M. Hatala, P. Beraxa, J. Duplák and J. Zajac. "Determination of CVD coating thickness for shaped surface tool." TEM Journal, vol. 7(2), pp. 428-432, 2018.

[3] R. Davis, A. Singh, S. Kachhap and N. Nath. "A comparative study of EDD and PM-EDD in producing holes in inconel 718 alloy." Key Engineering Materials, vol. 833, pp. 48-53, 2020.

[4] E. Evin, M. Tomáš and J. Kmec. "Optimization of electrodischarge texturing parameters for steel sheets' finishing rollers." Materials, vol. 13(5), art. no. 1223, 2020.

[5] S. Hamed, L.A. Al-Juboori, V.N. Najm and A.M. Saleh. "Analysis the impact of WEDM parameters on surface microstructure using response surface methodology." ASET 2020, Advances in Science and Engineering Technology International Conferences, Dubai, 4-9 February 2020, art no. $9118208,2020$.

[6] S. Hašová and L. Straka. "Design and verification of software for simulation of selected quality indicators of machined surface after WEDM." Academic Journal of Manufacturing Engineering, vol. 14(2), pp. 13-20, 2016.

[7] E. Kuznetsov, V. Nahornyi and T. Krenicky. "Gas Flow Simulation in the Working Gap of Impulse Gas-barrier Face Seal." Management Systems in Production Engineering, vol. 28(4), pp. 298-303, 2020. 
[8] J. Maščenik. "Implementation of the designed program for calculation and check of chain gears." MM Science Journal, vol. 2019 (december), pp. 3431-3434, 2019.

[9] K. Mouralova, L. Benes, J. Bednar, R. Zahradnicek, T. Prokes and J. Fries. "Analysis of machinability and crack occurrence of steels 1.2363 and 1.2343ESR machined by die-sinking EDM." Coatings, vol. 10(4), art. no. 406, 2020.

[10] V. Ngocpi, D.T. Tam, N.M. Cuong and T.H. Tran. "Multi-objective optimization of PMEDM process parameters for processing cylindrical shaped parts using taguchi method and grey relational analysis." International Journal of Mechanical and Production Engineering Research and Development, vol. 10(2), pp. 669-678, 2020.

[11] Š. Olejarova and T. Krenicky. "Monitoring the condition of the spindle of the milling machine using vibration." $M M$ Science Journal, vol. 2016(11), pp. 1227-1231, 2016.

[12] A. Panda, Š. Olejárová, J. Valíček and M. Harničárová." Monitoring of the condition of turning machine bearing housing through vibrations." The International Journal of $\mathrm{Ad}$ vanced Manufacturing Technology, vol. 97(1-4), pp. 401411, 2018.

[13] A. Panda, V. Nahornyi, I. Pandová, M. Harničárová, M. Kušnerová, J. Valíček and J. Kmec. "Development of the method for predicting the resource of mechanical systems." The International Journal of Advanced Manufacturing Technology, vol. 105(1-4), pp. 1563-1571, 2019.

[14] M. Pollák and J. Tkáč. "Enterprise information data management system for small manufacturing company." TEM Journal - Technology, Education, Management, Informatics, vol. 8(4), pp. 1169-1175, 2019.

[15] J.E.A. Qudeiri, A. Saleh, A. Ziout, A.H.I. Mourad, M.H. Abidi and A. Elkaseer. "Advanced Electric Discharge Machining of Stainless Steels: Assessment of the State of the Art, Gaps and Future Prospect." Materials, vol. 2019(12), a.no. 907, 2019.

[16] M. Rimár, M. Fedák, A. Kulikov and P. Šmeringai. "Study of gaseous flows in closed area with forced ventilation." MM Science Journal, vol. 2018(3), pp. 2188-2191, 2018.

[17] P. Shandilya, P.K. Jain and N.K. Jain. "Modelling and process optimisation for wire electric discharge machining of metal matrix composites." International Journal of Machining and Machinability of Materials, vol. 18, pp. 119-1207, 2016.

\author{
L'uboslav Straka \\ ORCID ID: 0000-0003-0914-2155 \\ Technical University of Kosice with a seat in Prešov \\ Faculty of Manufacturing Technologies \\ Department of Automotive \\ and Manufacturing Technologies \\ Štúrova 31, Prešov, Slovakia \\ e-mail: luboslav.straka@tuke.sk,
}

\section{Patrik Kuchta}

Technical University of Kosice with a seat in Prešov

Faculty of Manufacturing Technologies

Department of Automotive

and Manufacturing Technologies

Štúrova 31, Prešov, Slovakia

e-mail: patrik.kuchta@tuke.sk
[18] L'. Straka and G. Dittrich. "Influence of tool steel properties on surface quality after electrical discharge machining by wire electrode." The International Journal of Advanced Manufacturing Technology, vol. 106(5-6), pp. 1617-1632, 2020.

[19] L'. Straka, I. Čorný, J. Pitel' and S. Hašová. "Statistical Approach to Optimize the Process Parameters of HAZ of Tool Steel EN X32CrMoV12-28 after Die-Sinking EDM with SFCu Electrode." Metals, vol. 7(2), pp. 1-22, 2017.

[20] L'. Straka and S. Hašová. "The critical failure determination of the constructional parts of autonomous electroerosion equipment by applying Boolean logic. "Academic Journal of Manufacturing Engineering, vol. 14(2), pp. 80-86, 2016.

[21] L'. Straka and G. Dittrich. "Intelligent control system of generated electrical pulses at discharge machining." Emerging trends in mechatronics, IntechOpen, 26 p., 2020.

[22] L. Sukhodub, A. Panda, K. Dyadyura, I. Pandová and T. Krenický. "The design criteria for biodegradable magnesium alloy implants." MM Science Journal, vol. 2018(December), pp. 2673-2679, 2018.

[23] D. Oniszczuk-Swiercz, R. Swiercz, T. Chmielewski and T. Salacinski. "Experimental investigation of influence WEDM parameters on surface roughness and flatness deviation." Metal 2020, vol. 29, p. 611-617, 2020.

[24] D.O. Świercz and R. Świercz. "EDM - analyses of current and voltage waveforms." Mechanik, vol. 2, pp. 1-3, 2017.

[25] R. Swiercz, and R. Holubek. "Experimental investigation of influence electrical discharge energy on the surface layer properties after EDM." Welding Technology Review, vol. 92(5), pp. 7-13, 2020.

[26] J. Wang, J.A. Sánchez, B. Izquierdo and I. Ayesta. "Experimental and numerical study of crater volume in wire electrical discharge machining." Materials, vol. 13(3), art. no. 577, 2020.

[27] M.T. Yan and T.Ch. Lin. "Development of a Pulse Generator for Rough Cutting of Oil-based Micro Wire-EDM." ISEM XVIII, Procedia CIRP, vol. 42, pp. 709-714, 2016.

[28] D. Zhou, Ch. Sun, Y. Zhang and P. Wang. "A noncontact fullfield flatness measuring system based on fringe projection." Proceedings of SPIE, vol. 11439, art.no. 114391B, 2020. 